\title{
Hervé Guibert, 20 ans après
}

\author{
Arnaud Genon \\ Nottingham Trent University
}

Dans la nuit du 12 au 13 décembre 1991, Hervé Guibert, atteint du virus du sida, fit une tentative de suicide. Transporté à l'hôpital Béclère à Clamart, il y mourut le 27 décembre. Voilà aujourd'hui vingt ans que l'auteur de À l'ami qui ne m'a pas sauvé la vie (1990) - pour ne citer que le plus célèbre de ses romans - a disparu. Il a laissé derrière lui une œuvre littéraire protéiforme, composée notamment de romans, de nouvelles, d'autofictions, de journaux, de contes, d'un essai, d'un romanphoto, d'une pièce de théâtre et de textes inclassables, à l'image de Vice (1991), recueil à la frontière de l'inventaire et de l'album photographique. À cet ensemble, il faut ajouter de très nombreux articles journalistiques consacrés à la photographie 
(1999) ou à la vie culturelle en général (2008), un film, $L a$ Pudeur ou l'Impudeur (2009) et une œuvre photographique dont la Maison européenne de la photographie a souligné l'importance et la qualité en proposant, de février à avril 2011, une rétrospective lors de laquelle plus de deux cent clichés ont été exposés.

Ce vingtième anniversaire de la mort de l'écrivain est l'occasion de tirer un nouveau bilan critique qui vient réactualiser ceux effectués rapidement après sa disparition par Jean-Pierre Boulé en 1995 et par Ralph Sarkonak en 1997: qu'en est-il de l'œuvre d'Hervé Guibert aujourd'hui ? Comment la lit-on? Que retient-on des différents aspects qu'elle revêt?

En 2004, je proposai un état des lieux des études guibertiennes (Genon, 2004) afin de tenter de cartographier l'étendue des travaux qui avaient été réalisés sur l'écrivainphotographe. À la fin de cette synthèse, je m'interrogeai sur l'avenir des études guibertiennes, que je qualifiai, à l'époque, de « moroses ». Je remarquai que l'œuvre de Guibert traversait son "purgatoire», qu'elle n'avait pas l'écho qu'elle me semblait mériter. Force est de constater que, depuis cette date, le constat n'est plus le même. L'œuvre de Guibert, qui rentrait alors timidement et péniblement à l'Université, souvent dans le cadre de recherches de troisième cycle, y est maintenant enseignée dans des cours ou des séminaires portant sur la littérature contemporaine, sur l'autobiographie ou sur la presse dans plusieurs facultés françaises (l'Université de Provence, l'Université Michel de Montaigne Bordeaux III, l'Université de Paris X Nanterre, etc.). Elle fait aussi l'objet d'études dans des universités étrangères (Université de Toronto, de Montréal, Nottingham Trent, etc.), de conférences, de thèses, de mémoires 
de masters et de publications régulières. Un site Internet lui est consacré (http://herveguibert.net) et s'est donné pour mission de suivre l'actualité des travaux et des manifestations qui touchent à son œuvre. À cela s'est ajoutée, ces dernières années, une actualité éditoriale riche avec les rééditions de plusieurs de ses livres, la publication de ses Articles intrépides (2009), l'édition en DVD de La Pudeur ou l'Impudeur, la diffusion de documentaires portant sur certains aspects de son travail (Autofictions de Dominique Gros, Guibert cinéma d'Anthony Doncque) ou encore l'organisation d'une exposition rétrospective de ses photographies à la M.E.P, comme nous le disions plus haut.

L'œuvre d'Hervé Guibert est donc vivante dans sa pluralité. On ne se cantonne désormais plus au seul aspect de l'écrivain et de la maladie - même s'il est impossible de faire l'impasse sur cette question -, mais on interroge aussi ses textes sur la photographie, ses photographies, son film, les relations intertextuelles qu'entretiennent certaines de ses œuvres avec des écrivains tels que Roland Barthes ou Thomas Bernhard. On reconnaît ainsi Hervé Guibert comme un artiste ayant investi, avec succès, différentes formes de création et non plus comme un écrivain qui aurait eu, à côté de son travail littéraire, des lubies artistiques secondaires sur lesquelles il ne faudrait pas se pencher sérieusement. La richesse de ce dossier qu'accueille la revue de critique et de théorie littéraire @nalyses en est la preuve puisqu'il cherche à cerner Guibert l'écrivain, Guibert le photographe, Guibert le cinéaste, Guibert le journaliste. Il révèle aussi que la pluralité de ces pratiques, des formes explorées n'est pas le signe d'un éclatement de son travail, d'une dispersion d'un talent mais au contraire d'une cohérence interne impressionnante, comme si l'œuvre était un 
corps où chaque élément circule de manière fluide, se répond, se fait écho, dans ce qui relève d'une nécessité organique.

Car tous les champs artistiques traversés par Guibert ne sont finalement que différents moyens pour se dire, pour explorer son identité, pour repousser les limites du dévoilement de soi. C'est dans l'écriture de ce «je» que réside l'unité de l'entreprise de l'auteur, comme l'a montré Jean-Pierre Boulé dans un des livres qu'il lui a consacrés (2001) et comme le remarquait Guibert lui-même: «J'ai été frappé par l'introduction des Essais de Montaigne qui disait : “J'ai voulu me peindre nu", ça a fait tilt, je me suis dit que c'était quelque chose que je pourrais mettre en exergue à tout ce que j'ai fait, enfin de beaucoup de choses que j'ai écrites » (1992, p. 145). Ce « je», Guibert l'a décliné dans l'ensemble de ses textes: dans ses autofictions et son journal, bien sûr, mais aussi, plus inattendu, dans ses articles journalistiques, où son regard est toujours singulier, subjectif, intime ; dans ses photographies, qui se lisent comme l'album de son univers personnel; dans son film, où le sujet va jusqu'à filmer une tentative de suicide et faire de sa propre disparition au monde un acte de création...

C'est sur ce «je» et le monde qu'il a créé que les contributeurs de ce dossier ont accepté de revenir. Le constat est heureux : ils se sont penchés sur les différentes facettes de l'œuvre de Guibert, signe de l'évolution du regard qui est désormais porté sur son travail. Les articles interrogent la manière dont se construisent l'identité du sujet et l'identité scripturaire et en soulignent leur caractère «autoréflexif et spéculaire ». D’autres questionnent la scopophilie — ou pulsion scopique - qui amena l'écrivain-photographe-cinéaste à devenir un capteur, voire un prédateur d'images. Les relations 
intertextuelles que tissent nombre de ses textes avec les auteurs qu'il admirait sont aussi abordées. Dans un entretien avec Didier Éribon, Guibert évoquait d'ailleurs en ces termes son rapport aux autres écrivains :

Je crois qu'on est écrivain en étant lecteur. L'écrivain que je lisais ou son ombre, ou son fantôme devenait presque un personnage de fiction que j'écrivais. C'est à la fois un personnage et un modèle. Je n'ai jamais eu le fantasme de la modernité, de l'invention littéraire. Je n'aurais jamais voulu faire quelque chose de neuf, de nouveau. J'avais ces amours pour des écrivains et j'essayais de me laisser porter par eux. (1991a, p. 88)

Cette caractéristique de l'écriture guibertienne est ici explorée dans différentes perspectives, dans les relations à Eugène Savitzkaya ou à Thomas Bernhard. Enfin, le Guibert journaliste n'est pas oublié. Les Articles intrépides, récemment publiés, font déjà l'objet d'études très riches.

Vingt ans après la disparition de l'écrivain, la revue @nalyses offre un nouveau bilan. Comme les autres, il n'est que provisoire, il n'est qu'une photographie, qu'un instantané qui révèle la manière dont est aujourd'hui perçu le travail de Guibert. Qu'il ouvre des pistes, des perspectives et participe et à la dynamique des études guibertiennes est notre seule ambition. 


\section{Bibliographie}

Boulé, Jean-Pierre. (2001), Hervé Guibert: L'entreprise de l'écriture du moi, Paris, L'Harmattan, coll. «Critiques littéraires ».

—. (dir.). (1995), Hervé Guibert, Nottingham French Studies, vol. 34 , no 1 , printemps.

GENON, Arnaud. (2004), « Hervé Guibert en 2004 : état des lieux des études guibertiennes », Acta Fabula, printemps, vol. 5, no 2 .

GuiBert, Hervé (2009), La Pudeur ou l'Impudeur, Paris, BQHL.

—. (2008), Articles intrépides, Paris, Gallimard.

—. (1999), La Photo, inéluctablement, Paris, Gallimard.

—. (1994), La Piqûre d'amour et autres textes suivi de La Chair fraîche, Paris, Gallimard.

-. (1992), «Pour répondre à quelques questions qui se posent... », entretien avec Christophe Donner, La Règle $d u$ jeu, vol. 3, n 7, mai, p. 135-157.

-. (1991), Vice, Paris, Jacques Bertoin.

—. (1991a), "Hervé Guibert et son double », entretien avec Didier Éribon, Le nouvel Observateur, 18 juillet, p. 87-89.

—. (1990), À l'ami qui ne m'a pas sauvé la vie, Paris, Gallimard.

SARKONAK, Ralph (dir.). (1997), Le Corps textuel d'Hervé Guibert, Paris-Caen, Minard, La Revue des Lettres Modernes. 